DOI: $10.1590 / 1089-68916 \mathrm{i} 127789$

PRODUÇÃO ANIMAL

\title{
EFEITO DO Lactobacillus plantarum NO TRATO INTESTINAL DE ALEVINOS DE Oreochromis niloticus
}

\section{Lactobacillus plantarum EFFECT ON INTESTINAL TRACT OF Oreochromis niloticus FINGERLINGS}

\author{
Adolfo Jatobá ${ }^{1}$ \\ José Luís Pedreira Mouriño² \\ ${ }^{1}$ Professor Doutor do Instituto Federal Catarinense Campus de Araquari, Araquari, SC, Brasil - \\ adolfo.jatoba@ifc-araquari.edu.br \\ ${ }_{2}^{2}$ Professor Doutor da Universidade Federal de Santa Catarina, Florianópolis, SC, Brasil.
}

\section{Resumo:}

O objetivo deste trabalho foi avaliar as alterações na microbiota do trato intestinal e desempenho zootécnico de alevinos de tilápia do Nilo (Oreochromis niloticus) alimentados com dietas suplementadas com Lactobacillus plantarum. Cento e vinte alevinos revertidos sexualmente foram distribuídos em seis caixas, divididos em dois tratamentos, em triplicata: alevinos alimentados com dieta suplementa com L. plantarum e alevinos alimentados com dieta controle. Após 42 dias, as tilápias alimentadas com a dieta suplementada com L. plantarum apresentaram maior número de bactérias ácido-lácticas, $3,5 \times 10^{4}$ UFC e $1,1 \times 10^{2}$ UFC por g de trato, e menor de bactérias totais, $5,8 \times 10^{6}$ UFC e $5,2 \times 10^{7}$ UFC por $\mathrm{g}$ de trato intestinal, em relação aos alimentados com dieta controle, além de incrementar em 3,9\% o ganho em peso semanal, 15,6\% a biomassa final e 15,5\% eficiência alimentar. O uso de probiótico na alevinagem de tilápia eleva a produtividade.

Palavras-chave: cultivo de peixes; probióticos; tilápia.

\begin{abstract}
:
The objective of this study was to evaluate alterations in the intestinal tract microbiota and growth performance of Nile tilapia (Orechromis niloticus) fed diets supplemented with Lactobacillus plantarum. One hundred and twenty sexually reversed fingerlings were stocked in six aquaria and divided into two treatments, in triplicate: fingerlings fed diet supplement with L. plantarum and fingerlings fed control diet. After 42 days, tilapia fed the diet supplemented with L. plantarum had higher amount of lactic acid bacteria, $3,5 \times 10^{4} \mathrm{CFU}$ and $1,1 \times 10^{2} \mathrm{CFU}$ per $\mathrm{g}$ tract, and lower total

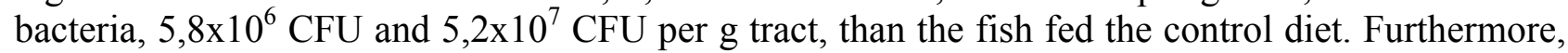
probiotics increased 3,9\% the weekly weight gain, 15,6\% final biomass and 15,5\% feed efficiency. The use of probiotics in tilapia hatcheries boosts productivity.
\end{abstract}

Keywords: fishculture; probiotic; tilapia.

Recebido em: 23 dez. 2013

Aceito em 29 out. 2014-10-29 


\section{Introdução}

A piscicultura é uma atividade em plena expansão no Brasil e, entre a diversidade de espécies cultivadas, destaca-se a Tilápia do Nilo (Oreochromis niloticus), sendo a mais produzida em território nacional ${ }^{(1)}$; entretanto, a falta de alevinos restringe o crescimento da tilapicultura.

A quantidade e qualidade de larvas e alevinos está diretamente relacionada com o sucesso nos sistemas de produção aquícolas ${ }^{(2)}$. A falta de alevinos limita o crescimento desta atividade e, entre os principais fatores limitantes da produção de alevinos, podem-se destacar o manejo nutricional inadequado e o surgimento de enfermidades emergentes. Como medida profilática, a utilização de probióticos eleva a imunocompetência dos peixes garantindo melhor qualidade sanitária dos alevinos $^{(3-5)}$, assim como aumenta a vilosidade das células do epitélio intestinal ${ }^{(6)}$ e aumentar a produtividade $^{(7)}$.

Para aquicultura, Gatesoupe ${ }^{(8)}$ definiu probióticos como células microbianas que são adicionadas de maneira que entrem no trato digestivo dos animais, mantendo-se vivas, com o objetivo de melhorar a saúde do animal, excluindo a possibilidade dos probióticos atuarem no meio (ambiente de cultivo), como definido por Verschuere et al. ${ }^{(9)}$. Entre os micro-organismos com potencial probiótico, as bactérias ácido-lácticas têm destaque devido a sua capacidade de inibir o crescimento de bactérias patogênicas pela produção de compostos antibacterianos ${ }^{(10)}$ e sua ação imunoestimulante ${ }^{(3,11-14)}$. Entre os compostos produzidos destacam-se o ácido láctico, ácido acético, peróxido de hidrogêndaio, reuterina e bacteriocinas ${ }^{(14)}$.

No trato intestinal dos animais aquáticos, há uma grande diversidade de micro-organismos patogênicos e/ou benéficos, e esta população pode variar de acordo com o meio ambiente, disponibilidade de nutrientes, saúde e nutrição do hospedeiro, ou pelo uso de probióticos, prebióticos e simbióticos ${ }^{(4,8)}$.

O objetivo deste trabalho foi avaliar as alterações na microbiota do trato intestinal e desempenho zootécnico de alevinos de tilápia do Nilo (Orechromis niloticus) alimentados com dietas suplementada com uma cepa de bactéria ácido-láctica isolada de Tilápias do Nilo.

\section{Material e Métodos}

O experimento foi realizado nos meses de março e abril de 2013, com duração de 35 dias, no Laboratório de Aquicultura do Instituto Federal Catarinense - Câmpus Araquari, Araquari, Santa Catarina, Brasil. Este trabalho seguiu todas as diretrizes da prática de eutanásia do CONCEA (Conselho Nacional de Controle de Experimentação Animal), protocolo n ${ }^{\circ}$ 0006/2013.

Para a seleção da bactéria ácido-láctica, foram coletados três alevinos de Tilápia do Nilo (Oreochromis niloticus) saudáveis, oriundos do Laboratório de Aquicultura do Instituto Federal Catarinense - câmpus Araquari, com peso médio de $43 \mathrm{~g}$. Os alevinos foram anestesiados com óleo de cravo (1\%) e eutanasiados por meio da secção da medula espinhal, amostras do trato intestinal foram retiradas com assepsia, maceradas com solução salina estéril $0,65 \%$ de $\mathrm{NaCl}$ (SSE) e semeadas em placas de Petri com meio de cultura Agar Man Rogosa Sharpe ${ }^{(15)}$ modificado por Ramirez et al. ${ }^{(16)}$, assim como descrito por Jatobá et al. ${ }^{(3)}$. A cepa isolada foi identificada bioquimicamente (API 50-CHL, bioMérieux). 
Após identificação, a cepa de bactéria ácido-láctica foi submetida a teste de inibição in vitro, contra bactérias patogênicas (Vibrio harveyi, V. anguillarum, V. alginolyticus, Enterococcus durans, Micrococcus luteus e Escherichia coli) para animais aquáticos. Utilizou-se o método de Tagg e McGiven ${ }^{17}$ adaptado por Ramirez et al. ${ }^{(16)}$, no qual placas de Petri contendo meio Agar MRS foram semeadas com uma das cepas de bactéria ácido-láctica isolada anteriormente e incubadas à $35{ }^{\circ} \mathrm{C}$ por 48h; em seguida, foram retirados três discos de Agar MRS de 0,8 cm de diâmetro contendo as cepas de bactérias ácido-lácticas e colocados em meio de cultura Agar Triptona de Soja (TSA), semeado com um dos patógenos. O processo foi repetido para todas as cepas isoladas. Essas placas foram incubadas a $30{ }^{\circ} \mathrm{C}$ por $24 \mathrm{~h}$, pelo método de Tagg e McGiven ${ }^{(17)}$ descrito por Jatobá et al. ${ }^{(3)}$. Os resultados foram comparados com os dados do mesmo autor.

A dieta experimental foi misturada com a bactéria ácido-láctica crescida em meio de cultura MRS, na concentração de 4,6×10 $0^{8}$ unidade formadora de colônia (UFC). $\mathrm{mL}^{-1}$, na proporção de $100 \mathrm{~mL} \mathrm{~kg}{ }^{-1} \mathrm{de}$ ração em pó comercial (proteína bruta $45 \%$, umidade $10 \%$, gordura $8 \%$, fibra bruta $2,8 \%$, fósforo $1,5 \%$, tamanho $1 \mathrm{~mm}$, extruda, Guabi Brasil). A mistura foi incubada durante $24 \mathrm{~h}$ a $35{ }^{\circ} \mathrm{C}$ em recipiente hermeticamente fechado. Após este período, os recipientes contendo as rações foram abertos e secados em estufa por $24 \mathrm{~h}$ a $35{ }^{\circ} \mathrm{C}$. A ração do tratamento controle foi aspergida apenas com meio de cultura MRS estéril. Para a quantificação de bactérias ácido-láticas na ração, foram realizadas cinco diluições seriadas fator 1:10. A dieta suplementada com a bactéria ácido-láctica foi considerada apta para uso, quando a contagem foi acima de $1 \times 10^{7}$ UFC.g ${ }^{-1}$.

Os alevinos de Tilápia do Nilo (O. niloticus) foram oriundos do Laboratório de Aquicultura do Instituto Federal Catarinense - câmpus Araquari. Os mesmos foram obtidos através de reprodução natural e coletados para posterior reversão sexual por meio do fornecimento de $60 \mathrm{mg}$ de metiltestosterona por kg de ração, de acordo com a metodologia de Shelton et al. ${ }^{(18)}$.

Um total de 120 alevinos de tilápias nilótica sexualmente revertidos com peso médio inicial de $0,13 \pm 0,03 \mathrm{~g}$ foram distribuídos em seis caixas de polietileno $(40 \mathrm{~L})$, vinte peixes por unidade experimental, divididos em dois tratamentos: alevinos alimentados com dieta suplementada com bactérias ácido-láticas e controle, em triplicata. As caixas estavam em um sistema de recirculação, equipadas com filtro biológico, e mantidas à temperatura constante $\left(28-29^{\circ} \mathrm{C}\right)$.

Os alevinos eram alimentados quatro vezes ao dia (08:00, 11:00, 13:00 e 16:00 h), ad libitium. A temperatura e oxigênio dissolvido foram monitorados duas vezes ao dia (09:00 e 15:00 h). Amostras de água foram coletadas e semeadas em meio de cultura Agar MRS; para se identificar a presença de bactérias ácido-lácticas na água, as variáveis da qualidade da água $\mathrm{pH}$, total de amônia dissolvida, nitrito, e nitrato ${ }^{(19)}$ foram avaliadas semanalmente e as biometrias de todos os alevinos foram realizadas. Após este processo, os alevinos retornam à mesma unidade experimental.

Após cinco semanas de cultivo, foram avaliados peso final, comprimento, ganho em peso semanal, sobrevivência, biomassa final, eficiência alimentar, e influência das bactérias ácido-lácticas no trato intestinal dos alevinos.

Para avaliação no trato intestinal, no $35^{\circ}$ dia do experimento, foi encerrada a alimentação. Após $24 \mathrm{~h}$ de jejum, foi coletado um pool de cinco peixes de cada unidade experimental. Os peixes foram anestesiados com óleo de cravo (1\%) e eutanasiados por meio da secção da medula espinhal, amostras de aproximadamente $1,0 \mathrm{~g}$ do trato intestinal foram retiradas com assepsia para pesagem e maceração com o mesmo volume de SSE, cinco diluições seriadas (fator 1:10) foram realizadas para semeadura em placas de Petri com meio de cultura TSA e Agar MRS, para contagem de bactérias totais e bactérias ácido-lácticas, respectivamente. 
Para confirmar a presença da bactéria ácido-láctica oferecida na dieta no trato intestinal dos alevinos, algumas colônias foram coletadas da placa de contagem e identificadas bioquimicamente (API 50-CHL, bioMérieux). O perfil bioquímico obtido foi comparado com o da bactéria ácidoláctica utilizada no experimento.

Os dados foram previamente submetidos à análise de Bartlett para verificação da homogeneidade de variância. Os dados microbiológicos foram transformados em $\log _{(\mathrm{x}+1)}$. Posteriormente, foram submetidos ao teste " $t$ ". Todos os testes utilizaram um nível de significância de $5 \%$.

\section{Resultados e Discussão}

Dos alevinos de tilápia do Nilo, foram isoladas cinco cepas de bactérias ácido-lácticas, todas Gram positivas, três classificadas morfologicamente como cocos, um bacilo e um bacilococos. Entre as cepas isoladas, o bacilos demostrou um baixo crescimento, inferior a $10^{5} \mathrm{UFC} \cdot \mathrm{ml}^{-1}$ em condições laboratoriais, sendo descartada, pois a manutenção e sua taxa de crescimento são critérios de seleção para bactérias probióticas ${ }^{(21)}$. O bacilococos foi identificado bioquimicamente, com 99,9\% probabilidade para Lactobacillus plantarum. Diversos autores ${ }^{(3,7,11-14,21,22)}$ demonstraram o potencial probiótico de bactérias ácido-lácticas, em especial os lactobacilos.

O L. plantarum isolado neste trabalho demonstrou uma boa capacidade inibitória contra Vibrio harveyi $(16,0 \mathrm{~cm}), V$. anguillarum $(14,0 \mathrm{~cm})$, Enterococcus sp. $(15,0 \mathrm{~cm}), V$. alginolyticus $(13,0$ $\mathrm{cm})$, Micrococcus luteos $(22,0 \mathrm{~cm})$, Escherichia coli $(20,0 \mathrm{~cm})$, sendo seus resultados melhores que os observados por Jatobá et al. ${ }^{(3)}$ e Vieira et al. ${ }^{(21)}$. Outra vantagem na sua utilização é a redução no risco do desenvolvimento de resistência microbiana frente aos antibióticos, como já registrada para Enterococcus sp. frente à oxitetraciclina e eritromicina ${ }^{(24)}$, e para Vibrio harveyi, V. anguilarum $\mathrm{e}$ $V$. alginolyticus frente oxitetraciclina ${ }^{(3)}$.

$\mathrm{Na}$ alevinagem de tilápias não foram observadas diferenças significativas nas variáveis de qualidade de água entre os tratamentos, sendo registrados os valores máximos e mínimos, durante o experimento, para oxigênio dissolvido $\left(4,5-5,8 \mathrm{mg} \cdot \mathrm{L}^{-1}\right)$, temperatura $\left(28,1-29,6{ }^{\circ} \mathrm{C}\right), \mathrm{pH}(7,2-$ $7,4)$, amônia $\left(0,0-0,3 \mathrm{mg} \cdot \mathrm{L}^{-1}\right)$, nitrito $\left(0,0-0,2 \mathrm{mg} \cdot \mathrm{L}^{-1}\right)$ e nitrato $\left(0,0-0,1 \mathrm{mg} \cdot \mathrm{L}^{-1}\right)$. Este fato está relacionado com o sistema de recirculação, pois todas as unidades experimentais estavam ligadas no mesmo sistema, homogeneizando os parâmetros de qualidade de água. A presença do nitrato na água demostra que o processo de nitrificação estava ativo, convertendo amônia em nitrito e nitrito em nitrato ${ }^{(25)}$.

Não foi detectada a presença de bactérias ácido-lácticas na água das unidades experimentais alimentadas com ou sem dieta suplementada com bactérias ácido-lácticas. Este fato demostra que, apesar de os peixes estarem num sistema de filtros único, as bactérias não interferiram no tratamento controle. Este resultado corroborou o de Jatobá et al. ${ }^{(7)}$, que ofereceu dieta probiótica para tilápia do Nilo (O. niloticus) cultivada em sistema de policultivo com camarões marinhos (Litopenaeus vannamei) em um mesmo tanque e não observou a presença de bactérias ácidolácticas na água. É possível concluir que a água de cultivo não oferece os nutrientes necessários para esta bactéria se manter em concentrações viáveis.

Os alevinos de tilápia do Nilo alimentados com dieta suplementada com bactérias probióticas apresentaram maior ganho em peso semanal, comprimento, biomassa final e eficiência alimentar em relação aos alevinos alimentados com a dieta controle (Tabela 1). Apesar da maior sobrevivência 
(96,67\%) nos alevinos tratados com probióticos em relação ao controle $(86,67 \%)$, a diferença não foi considerada significativa.

A melhora da eficiência corroborou os achados de Jatobá et al. ${ }^{(7)}$, que observaram eficiência alimentar 13,6\% maior em tilápias do Nilo alimentadas com dieta suplementada com $L$. plantharum. Esses resultados podem estar associados com a capacidade de as bactérias ácidolácticas aumentarem a digestibilidade das dietas, como observado por Skrede et al. ${ }^{(26)} \mathrm{em}$ salmão do Atlântico alimentado com dieta suplementada com Lactobacillus sp., assim como pelas alterações na morfometria do intestino, como o aumento do tamanho, largura e do número das microvilosidades, e na espessura das células epiteliais de revestimento e número de células caliciformes da mucosa intestinal $^{(6,27)}$, permitindo uma melhor absorção dos nutrientes dos alevinos de tilápia alimentados com dietas suplementadas com L. plantarum.

Tabela 1: Índices zootécnicos de alevinos de tilápia do Nilo (Oreochromis niloticus) alimentados com dieta com ou sem suplementação de probióticos

\begin{tabular}{lrrr}
\hline \multirow{2}{*}{\multicolumn{1}{c}{ Indices Zootécnicos }} & \multicolumn{2}{c}{ Tratamento } & \multirow{2}{*}{ Significância } \\
\cline { 2 - 3 } & \multicolumn{1}{c}{ Controle } & \multicolumn{1}{c}{ Probiótico } & $(\boldsymbol{p})$ \\
\hline Peso Médio Final (g) & $5,30 \pm 0,02^{\mathrm{a}}$ & $5,40 \pm 0,05^{\mathrm{b}}$ & 0,001 \\
Comprimento Médio Final (cm) & $3,14 \pm 0,18^{\mathrm{a}}$ & $3,52 \pm 0,07^{\mathrm{b}}$ & 0,013 \\
Crescimento Semanal (g.semana $\left.{ }^{-1}\right)$ & $0,86 \pm 0,01^{\mathrm{a}}$ & $0,90 \pm 0,01^{\mathrm{b}}$ & 0,002 \\
Sobrevivência (\%) & $86,67 \pm 7,64^{\mathrm{a}}$ & $96,67 \pm 2,89^{\mathrm{a}}$ & 0,051 \\
Biomassa Final (g) & $106,24 \pm 4,04^{\mathrm{b}}$ & $93,91 \pm 7,95^{\mathrm{a}}$ & 0,025 \\
Eficiência Alimentar & $1,65 \pm 0,08^{\mathrm{a}}$ & $1,91 \pm 0,06^{\mathrm{b}}$ & 0,013 \\
\hline *Diferentes letras na linha indicam diferenças significativas $(p>0,05)$ & entre os tratamentos no teste-t.
\end{tabular}

A utilização de probióticos e seus efeitos sobre os índices zootécnicos geram resultados controversos. Meurer et al. ${ }^{(28)}$ e Suzer et al. ${ }^{(29)}$ não observaram incremento no ganho em peso, respectivamente, para tilápias alimentadas durante 30 dias com Saccharomyces cerevisiae e para Sparus aurata alimentados com Lactobacillus ssp.. Já Lara-Flores et al. ${ }^{(30)}$, Wang et al. ${ }^{(31)}$ e Jatobá et al. $^{(7)}$ observaram melhora do desempenho zootécnico das tilápias resultante do uso de probióticos, enquanto Carnevali et al. ${ }^{(22)}$, utilizando Lactobacillus ssp. isoladas do robalo europeu (Dicentrarchus labrax), registraram maior ganho em peso, de 60,0 a 85,0 $\mathrm{mg}$, nos rolabolos alimentados com dieta suplementada com probiótico contra $47 \mathrm{mg}$ no tratamento controle.

No trato intestinal dos alevinos de tilápia do Nilo foram observados um maior número de bactérias ácido-lácticas, $3,5 \times 10^{4}$ UFC e $1,1 \times 10^{2}$ UFC por $\mathrm{g}$ de trato, e menor número de bactérias totais, $5,8 \times 10^{6}$ UFC e $5,2 \times 10^{7}$ UFC por $\mathrm{g}$ de trato intestinal, para peixes alimentados com dieta suplementada com probiótico, em relação aos alimentados com dieta controle (Figura 1). Essas alterações na microbiota do trato intestinal já foram observadas em diversos animais aquáticos quando submetidos a tratamentos probióticos ${ }^{(3,7,11-13,23,27)}$ e, normalmente, elas são acompanhadas de um aumento no número de eritrócitos, células brancas (especialmente linfófitos) no sistema circulatório, sugerindo que os alevinos alimentados com a dieta probiótica estejam com uma melhor "imunocompetência", ou seja, sistema imunológico mais preparado para combater alguma enfermidade ou adversidade que possa surgir no ambiente de cultivo, que os animais alimentados com dieta sem probiótico (controle). 
No tratamento probiótico, as bactérias ácido-lácticas encontradas no trato intestinal foram reisoladas e identificadas como L. plantarum, com 99,9\% de probabilidade, e mesmo perfil bioquímico das bactérias suplementadas na dieta, sugerindo ser a mesma cepa de bactéria suplementada na dieta.

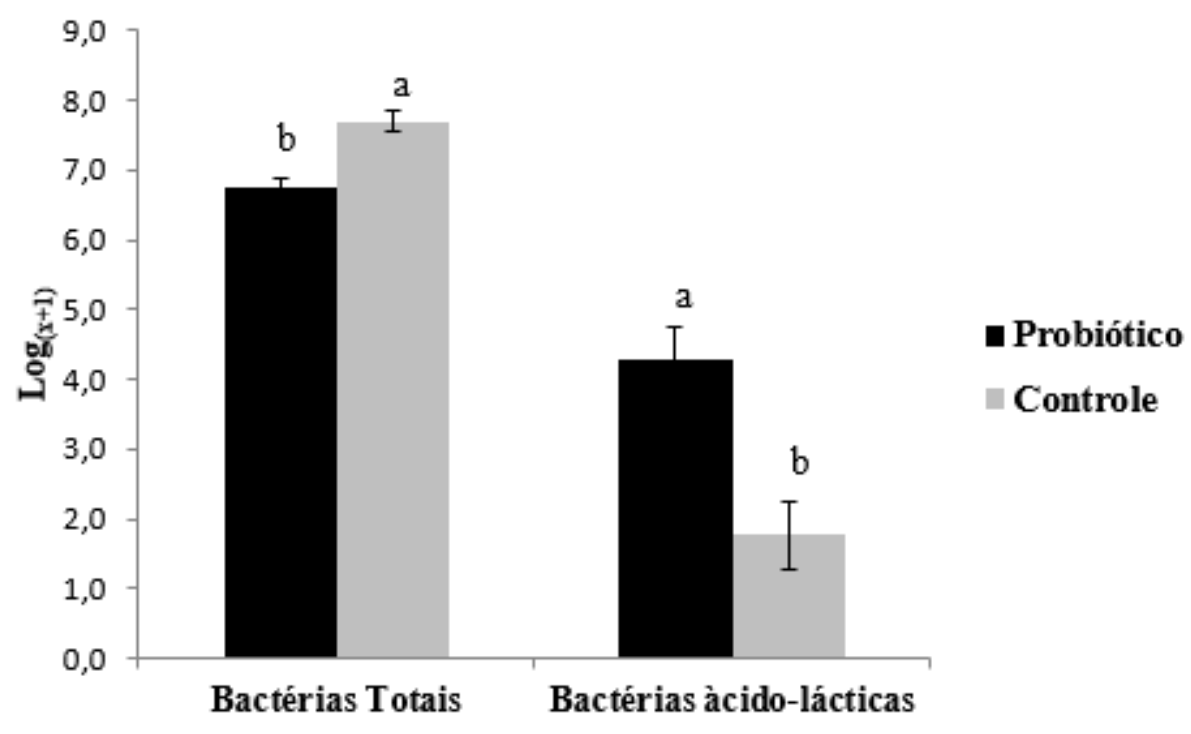

Figura 1. Unidade formadora de colônia (UFC) por g de trato intestinal de alevinos de tilápia do Nilo (Oreochromis niloticus) alimentados com dieta com ou sem suplementação de probióticos. Diferentes letras indicam diferenças significativas $(p>0,05)$ entre os tratamentos no teste-t.

\section{Conclusão}

O Lactobacillus plantarum exerce função probiótica para alevinos de tilápia do Nilo (Oreochomis niloticus), sendo indicado para incrementar a produtividade, eficiência alimentar e peso final dos alevinos, sem alterar a qualidade de água do sistema de produção.

\section{Agradecimentos}

Ao CNPq por fornecer uma bolsa para sua execução; GUABI por fornecer a dieta utilizada; ao Luiz Sérgio Moreira, Meliza Uller, Guilherme Katrucha e Karen Hartmann pelo apoio técnico para execução do mesmo. 


\section{Referências}

1. FAO (Food and Agriculture Organization of the United Nations). The state of world fisheries and aquaculture, Rome, Italia, 2013 Disponível em http://www.fao.org/fishery/statistics/en. Acesso em 20 dezembro de 2014.

2. Hayashi, C; Boscolo, WR; Soares, CM; Meurer, F. Exigência de proteína digestível para larvas de tilápia do Nilo (Oreochromis niloticus) durante a reversão sexual. Revista Brasileira de Zootecnia, 2002; 31(2):823828. Disponível em: http://www.scielo.br/pdf/rbz/v31n2s0/21269.pdf. Acesso em 20 dezembro de 2014.

3. Jatobá, A; Vieira, FN; Buglione, C; Silva, BC; Mouriño, JLP; Jerônimo, GT; Dotta, G; Martins, ML. Lactic-acid bacteria isolated from the intestinal tract of Nile tilapia utilized as probiotic. Pesquisa Agropecuária Brasileira, 2008;43(9):1201-1207. Disponível em: http://www.scielo.br/pdf/pab/v43n9/15.pdf . Acesso em 20 dezembro de 2014.

4. Merrifield, D L; Dimitroglou, A; Foey, A; Davies, S.J; Baker, RTM; Bogwalg, J; Castex, M; Ringo, E. The current status and future focus of probiotic and precbiotic applications for salmonids. Aquaculture, 2010;302:1-18. Disponível em: http://dx.doi.org/10.1016/j.aquaculture.2010.02.007. Acesso em 20 dezembro de 2014.

5. Dimitroglou, A; Merrifield, DL; Carnevali, O; Picchietti, S; Avella, M; Daniels, CL; Güroy, D; Davies, SJ. Microbial manipulations to improve fish health and production: A Mediterranean perspective. Fish and Shelfish Immunology, 2011;30:1-16. Disponível em: http://dx.doi.org/10.1016/j.fsi.2010.08.009. Acesso em 20 dezembro de 2014.

6. Mello, H; Moraes, JRE; Niza, IG; Moraes, FR; Ozório, ROQ; Shimada, MT, Engracia Filho, JR; Claudiano, GS. Efeitos benéficos de probióticos no intestino de juvenis de Tilápia-do-Nilo. Pesquisa Veterinária Brasileira, 2013;33(6):724-730. Disponível em http://dx.doi.org/10.1590/S0100736X2013000600006. Acesso em 20 dezembro de 2014.

7. Jatobá, A; Vieira, FN; Buglione-Neto, CC; Mouriño, JLP; Silva, BC; Seiftter, WQ; Andreatta, RE. Diet supplemented with probiotic for Nile tilapia in polyculture system with marine shrimp. Fish Physiology and Biochemestry, 2011;37:725-732.

8. Gatesoupe, F J. The use of probiotics in aquaculture. Aquaculture, v. 180, p. 147-165, 1999.

9. Verschuere, L; Rombaut, G; Sorgeloos, P; Verstraete, W. Probiotic Bacteria as Biological Control Agents in Aquaculture. Microbiology and Molecular Biology Reviews, 2000;64:655-671. Disponível em: http://www.ncbi.nlm.nih.gov/pmc/articles/PMC99008/. Acesso em 20dezembro de 2014.

10. Fuller, R. Probiotics in man and animals, a review. Journal of Applied Bacteriology, 1989;66:365-378.

11. Vieiria, FN; Pedrotti, FS; Buglione, CC; Mouriño, JLP Beltrame, E; Martins, ML; Ramires, C; Vinatea, LA. Lactic-acid bacteria increase the survival of marine shrimp, Litopenaeus vannamei, after infection with Vibrio harveyi. Brazilian Journal of Oceanography, 2007;55(4):251-255. Disponível em: http://dx.doi.org/10.1590/S1679-87592007000400002. Acesso em 20dezembro de 2014.

12. Vieira, FN; Buglione, CC; Mouriño, JLP.; Jatobá, A; Ramires, C; Martins, ML.; Barracco, MAAM; Vinatea, LA.Time-related action of Lactobacillus plantarum in the bacterial microbiota of shrimp digestive tract and its action as inmunostimulation. Pesquisa Agropecuária Brasileira, 2008;43(6):763-769. Disponível em: http://dx.doi.org/10.1590/S0100-204X2008000600013. Acesso em 20 dezembro de 2014.

13. Vazquez, JA; Gonzalez, MP; Murado, MA. Effects of lactic acid bacteria cultures on pathogenic microbiota from fish. Aquaculture, 2005;245:149-161. Disponível em: http://dx.doi.org/10.1016/j.aquaculture.2004.12.008 . Acesso em 20 dezembro de 2014.

14. Gatesoupe, F J. Updating the importance of lactic acid bacteria in fish farming: natural occurrence and probiotic treatments. Journal Molecular Microbiology Biotechnology, 2008;14(1):107-114. Disponível em: http://archimer.ifremer.fr/doc/2007/publication-2589.pdf. 
15. De Man, JC; Rogosa, M; Sharpe, ME. A media for the cultivation of lactobacilli. Journal Applied Bacteriology, 1960;23:30-135. Disponível em: http://dx.doi.org/10.1111/j.1365-2672.1960.tb00188.x. Acesso em 20 dezembro de 2014.

16. Ramírez, C; Bolívar, A; Ciffoni, GA; Pancheniak, EMG; Soccol, EFRC. Microorganismos lácticos probióticos para ser aplicados en la alimentación de larvas de camarón y peces como substituto de antibiótico. La Alimentación Latino Americana, 2006;264:70-78.

17. Tagg, JR \& Mc Given, AR. Assay system for bacteriocins. Applied Microbiology. 1971;21:943. Disponível em: http://www.ncbi.nlm.nih.gov/pmc/articles/PMC377313/pdf/applmicro00115-0157.pdf. Acesso em 20 dezembro de 2014.

18. Shelton, WL; Rodrigues-Guerrero, D; Lopes, MJ Factors affecting androgen sex reversal of Tilápia aurea. Aquaculture, 1981;25(1):59-65. Disponível em: http://dx.doi.org/10.1016/0044-8486(81)90099-5. Acesso em 20 dezembro de 2014.

19. Strickland, JDH, Parsons, TR, 1972. A Practical Handbook of Seawater Analysis. vol. 167. Bulletin of Fisheries Research Board, Canada, pp. 310.

20. Zar, JH. Biostatistical analysis. $5^{\text {th }}$ ed. Pearson Prentice Hall, Upper Saddle River. NJ, 2010.

21. Vieira, FN; Jatobá, A; Mouriño, JLP; Vieira, PA; Soares, M; Silva, BC; Seiffert, WQ; Martins, ML; Vinatea, LA. In vitro selection of bacteria with potential for use as probiotics in marine shrimp culture. Pesquisa Agropecuária Brasileira, 2013;48(8):998-1004. Disponível em: http://dx.doi.org/10.1590/S0100204X2013000800027. Acesso em 20 dezembro de 2014.

22. Carnevali, O;Vivo, L; Sulpizio, R; Gioacchini, G; Olivotto, I; Silvi, S; Cresci, A. Growth improvement by probiotic in European sea bass juveniles (Dicentrarchus labrax, L.), with particular attention to IGF-1, myostatin and cortisol gene expression. Aquaculture, 2006:258:430-438. Disponível em: http://dx.doi.org/10.1016/j.aquaculture.2006.04.025. Acesso em 20 dezembro de 2014.

23. Barbosa, MC; Jatobá, A; Vieira, FN; Silva, BC; Mourino, JLP; Andreatta, RE; Seiffert, WQ; Cerqueira, VR. Cultivation of Juvenile Fat Snook (Centropomus parallelus Poey, 1960) Fed Probiotic in Laboratory Conditions. Brazilian Archives of Biology and Technology, 2011;54(4):795 - 801. Disponível em: http://dx.doi.org/10.1590/S1516-89132011000400020. Acesso em 20 dezembro de 2014.

24. Petersen, A; Dalsgaard, A. Antimicrobial resistance of intestinal Aeromonas spp. and Enterococcus spp. in fish cultured in integrated broiler-fish farms in Thailand. Aquaculture, 2003;219:71-82. Dispnível em: http://dx.doi.org/10.1016/S0044-8486(03)00018-8. Acesso em 20 dezembro de 2014.

25. Ebeling, JM; Timmons, MB; Bisogni, JJ. Engineering analysis of thestoichiometry of photoautotrophic, autotrophic, and heterotrophic removal ofammonia-nitrogen in aquaculture systems. Aquaculture, 2006;257:346-358. Disponível em: http://dx.doi.org/10.1016/j.aquaculture.2006.03.019. Acesso em 20 dezembro de 2014.

26. Skrede, G; Storebakken, T; Skrede, A; Sahlstrøm, S; Sørensen, M; Shearer, KD; Slinde, E. Lactic acid fermentation of wheat and barley whole meal flours improves digestibility of nutrients and energy in Atlantic salmon (Salmo salar L.) diets. Aquaculture, 2002;210:305-321. Disponível em: http://dx.doi.org/10.1016/S0044-8486(01)00851-1. Acesso em 20 dezembro de 2014.

27. Carvalho, JV; Lira, AD; Costa, SP; Moreira ELT, Pinto, LFB; Abreu RD; Albinati, RCB. Desempenho zootécnico e morfometria intestinal de alevinos de tilápia-do -Nilo alimentados com Bacillus subtilis ou mananoligossacarídeo. Revista Brasileira de Saúde e Produção Animal, 2011;12(1):176-187.

28. Meurer, F; Hayashi, C; Costa, MM; Mauerwerk, VL; Freccia, A. Utilização de Saccharomyces cerevisiae como probiótico para tilápias-do-nilo durante o período de reversão sexual submetidas a um desafio sanitário. Revista Brasileira de Zootecnia, 2006;35(5):1881-1886. Disponível em: http://dx.doi.org/10.1590/S1516-35982006000700001. Acesso em 20 dezembro de 2014.

29. Suzer, C; Çoban, D; Kamaci, HO; Saka, S; Firat, K; Otgucuoðlu, O; Küçüksari, H. Lactobacillus spp. bacteria as probiotics in gilthead sea bream (Sparus aurata, L.) larvae: Effects on growth performance and digestive enzyme activities. Aquaculture, 2008;280:140-145. Disponível em: http://dx.doi.org/10.1016/j.aquaculture.2008.04.020. Acesso em 20 dezembro de 2014. 
30. Lara-Flores, M; Olvera-Novoa MA; Guzmán-Méndez BE; López-Madrid W. Use of the bacteria Streptococcus faecium and Lactobacillus acidophilus, and the yeast Saccharomyces cerevisiae as growth promoters in Nile tilapia (Oreochromis niloticus). Aquaculture, 2003;216:193-201. Disponível em: http://dx.doi.org/10.1016/S0044-8486(02)00277-6. Acesso em 20 dezembro de 2014.

31. Wang J; LI, D; Dong, S; Wang, K; Tian, X. Experimental studies on polyculture in closed shrimp ponds I. Intensive polyculture of Chinese shrimp (Penaeus chinensis) with tilapia hybrids. Aquaculture, 1998;163:11-27. Disponível em: http://dx.doi.org/10.1016/S0044-8486(98)00165-3. Acesso em 20 dezembro de 2014.

Errata.

Na tabela 1, página 49, onde lê-se:

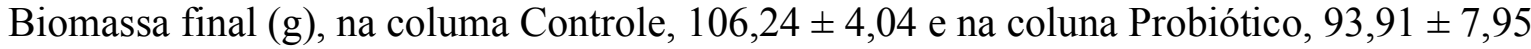

Deve-se ler:

Biomassa final (g), na coluna Controle 93,91 \pm 7,95 e na coluna Probiótico, 106,24 \pm 4,04 